\title{
Pengaruh DER, Perputaran Modal Kerja dan Ukuran Perusahaan Terhadap NPM pada Industri Farmasi Yang Listing di Bursa Efek Indonesia Periode 2012-2016
}

\author{
Susi Artati \\ Fakultas Ekonomi Universitas Batanghari
}

\begin{abstract}
Abstrack. Research Aims To Learn How does the Debt to Equity Ratio, Working Capital Turnover and Firm Size Against Net Profit Margin in the Pharmacy Industry in Indonesia Stock Exchange period 2012-2016 simultaneously and partially and how much influence the Debt to Equity Ratio, Working Capital Turnover and Firm Size Against Net Profit Margin in the Pharmacy Industry in Indonesia Stock Exchange period 2012-2016. The method used is quantitative descriptive method with independent variables, Debt to Equity Ratio, Working Capital Turnover and the Firm Size, while the dependent variable is Net Profit Margin. The analytical tool used in this research is multiple linear regression analysis, the classical assumption test, hypothesis test and coefficient of determination. The conclusion of this study indicate that the Debt to Equity Ratio, Working Capital Turnover and Firm size simultaneously significant affect on Net Profit Margin. In partial Working Capital Turnover significant affect on Net Profit Margin
\end{abstract}

Keyword : DER, Working Capital Turnover, Firm Size and NPM

\section{PENDAHULUAN}

Perusahaan merupakan bentuk badan usaha yang menjalankan setiap jenis usaha yang bersifat tetap dan terus menerus didirikan, bekerja, serta berkedudukan dalam wilayah negara Indonesia untuk tujuan memperoleh keuntungan atau laba (Kansil, 2001:2). Pendirian suatu perusahaan pada prinsipnya hendaklah diarahkan untuk mencapai tujuan pokok yaitu menjaga kelangsungan hidup perusahaan, memperbesar skala operasional perusahaan yang akhirnya dapat meningkatkan nilai perusahaan atau untuk memaksimalkan nilai perusahaan. Tujuan suatu perusahaan ialah untuk mendapatkan laba sehingga dibutuhkan laporan keuangan yang dapat menjadi acuan suatu perusahaan untuk mengetahui laba dan kerugian yang diperoleh perusahaan setiap tahunnya. Penelitian ini dilakukan untuk menguji kembali pengaruh debt to equity ratio, perputaran modal kerja dan ukuran perusahaan terhadap net profit margin, dimana penelitian ini merupakan pengembangan penelitian yang dilakukan (Nugroho, 2011). Perusahaan yang digunakan dalam penelitian ini adalah industri farmasi yang listing di Bursa Efek Indonesia. Industri farmasi merupakan bagian dari industri manufaktur yang bergerak di sektor obat-obatan. Sektor industri ini mengalami perkembangan karena obatobatan merupakan kebutuhan masyarakat dalam menjaga kesehatan setiap harinya. Industri farmasi termasuk industri yang berkembang pesat, hal ini terbukti dengan bertambahnya jumlah perusahaan yang terdaftar di Bursa Efek Indonesia dari tahun ke tahun.

Industri Farmasi yang terdaftar di Bursa Efek Indonesia sebanyak 10 (sepuluh) emiten, dari 10 (sepuluh) emiten hanya 8 (delapan) emiten sebagai sampel dalam penelitian ini yaitu PT. Darya Varia Laboratoria Tbk, PT. Indofarma Tbk, PT. Kimia Farma Tbk, PT. Kalbe Farma Tbk, PT. Merck Tbk, PT. Pyridam Farma Tbk, PT. Merck Sharp Dohme Pharma Tbk, PT. Tempo Scan Pasific Tbk. Data keuangan berupa debt to equity ratio, perputaran modal kerja, ukuran perusahaan net profit margin pada Industri Farmasi yang listing di Bursa Efek Indonesia selama periode 2012-2016 adalah sebagai berikut : 
Susi Artati, Pengaruh DER, Perputaran Modal Kerja dan Ukuran Perusahaan Terhadap NPM pada Industri Farmasi Yang Listing di Bursa Efek Indonesia Periode 2012-2016

Tabel 1

Perkembangan Debt to Equity Ratio pada Industri Farmasi di Bursa Efek Indonesia Selama Periode 2012-2016

\begin{tabular}{|c|l|c|c|c|c|c|c|}
\hline No & \multicolumn{1}{|c|}{$\begin{array}{c}\text { Emiten } \\
\text { Emale }\end{array}$} & $\mathbf{2 0 1 2}$ & $\mathbf{2 0 1 3}$ & $\mathbf{2 0 1 4}$ & $\mathbf{2 0 1 5}$ & $\mathbf{2 0 1 6}$ & Rerata \\
\hline $\mathbf{1}$ & PT Darya-Varia Laboratoria Tbk & 0.28 & 0.30 & 0.28 & 0.41 & 0.47 & 0.35 \\
\hline $\mathbf{2}$ & PT Indofarma Tbk & 0.83 & 1.19 & 1.11 & 1.59 & 1.64 & 1.27 \\
\hline $\mathbf{3}$ & PT Kimia Farma Tbk & 0.45 & 0.52 & 0.64 & 0.74 & 0.88 & 0.65 \\
\hline $\mathbf{4}$ & PT Kalbe Farma Tbk & 0.28 & 0.33 & 0.27 & 0.25 & 0.24 & 0.27 \\
\hline $\mathbf{5}$ & PT Merck Tbk & 0.37 & 0.36 & 0.29 & 0.35 & 0.29 & 0.33 \\
\hline $\mathbf{6}$ & PT Pyridam Farma Tbk & 0.55 & 0.86 & 0.79 & 0.58 & 0.54 & 0.66 \\
\hline $\mathbf{7}$ & PT Tempo Scan Pacific Tbk & 0.38 & 0.40 & 0.35 & 0.45 & 0.43 & 0.40 \\
\hline $\mathbf{8}$ & PT Merck Sharp Dhome Pharma Tbk & 24.48 & 70.83 & -31.04 & 13.98 & 4.78 & 16.61 \\
\hline Tertinggi & $\mathbf{2 4 . 4 8}$ & $\mathbf{7 0 . 8 3}$ & $\mathbf{1 . 1 1}$ & $\mathbf{1 3 . 9 8}$ & $\mathbf{4 . 7 8}$ & 23.04 \\
\hline Terendah & $\mathbf{0 . 2 8}$ & $\mathbf{0 . 3 0}$ & $\mathbf{- 3 1 . 0 4}$ & $\mathbf{0 . 2 5}$ & $\mathbf{0 . 2 4}$ & $-\mathbf{5 . 9 9}$ \\
\hline Rata-Rata Industri & $\mathbf{3 . 4 5}$ & $\mathbf{9 . 3 5}$ & $\mathbf{- 3 . 4 1}$ & $\mathbf{2 . 2 9}$ & $\mathbf{1 . 1 6}$ & 2.57 \\
\hline Perkembangan & - & $\mathbf{1 7 0 . 7 8}$ & $\mathbf{- 1 3 6 . 5 2}$ & $\mathbf{- 1 6 7 . 1 9}$ & $\mathbf{- 4 9 . 4 8}$ & -45.60 \\
\hline
\end{tabular}

Sumber: data olahan

Tabel 1 diatas dapat dilihat bahwa rata-rata industri mengalami kenaikan pada tahun 2013 sebesar $9,35 \%$ dengan nilai perkembangan sebesar $170,78 \%$. Pada data debt to equity ratio emiten yang mengalami peningkatan setiap tahunnya adalah PT Kimia Farma Tbk sedangkan perolehan angka terbesar pada data ini adalah PT Merck Sharp Dhome Pharma Tbk pada tahun 2013 sebesar 70,83\% dengan nilai rata-rata 16,61\%.

Tabel 2

Perkembangan Perputaran Modal Kerja pada Industri Farmasi di Bursa Efek Indonesia Selama Periode 2012-2016

\begin{tabular}{|c|l|c|c|c|c|c|c|}
\hline \multicolumn{1}{|c|}{$\begin{array}{c}\text { Nama } \\
\text { Emiten }\end{array}$} & $\mathbf{2 0 1 2}$ & $\mathbf{2 0 1 3}$ & $\mathbf{2 0 1 4}$ & $\mathbf{2 0 1 5}$ & $\mathbf{2 0 1 6}$ & Rerata \\
\hline $\mathbf{1}$ & PT Darya-Varia Laboratoria Tbk & 1.71 & 2.84 & 3.84 & 3.00 & 2.70 & 2.82 \\
\hline $\mathbf{2}$ & PT Indofarma Tbk & 4.40 & 0.20 & 1.82 & 1.58 & 7.52 & 3.10 \\
\hline $\mathbf{3}$ & PT Kimia Farma Tbk & 4.08 & 3.29 & 2.71 & 7.35 & 2.59 & 4.00 \\
\hline $\mathbf{4}$ & PT Kalbe Farma Tbk & 1.26 & 1.48 & 7.58 & 3.81 & 3.03 & 3.43 \\
\hline $\mathbf{5}$ & PT Merck Tbk & 1.85 & 7.39 & 3.03 & 1.55 & 1.75 & 3.11 \\
\hline $\mathbf{6}$ & PT Pyridam Farma Tbk & 7.32 & 4.80 & 2.80 & 2.80 & 6.02 & 4.75 \\
\hline 7 & PT Tempo Scan Pacific Tbk & 3.14 & 8.30 & 1.59 & $\mathbf{5 . 7 5}$ & 3.23 & 4.40 \\
\hline $\mathbf{8}$ & PT Merck Sharp Dhome Pharma Tbk & 2.13 & 2.12 & 3.47 & 2.47 & 4.97 & 3.03 \\
\hline Tertinggi & $\mathbf{7 . 3 2}$ & $\mathbf{8 . 3 0}$ & $\mathbf{7 . 5 8}$ & $\mathbf{7 . 3 5}$ & $\mathbf{7 . 5 2}$ & 7.61 \\
\hline Terendah & $\mathbf{1 . 2 6}$ & $\mathbf{0 . 2 0}$ & $\mathbf{1 . 5 9}$ & $\mathbf{1 . 5 5}$ & $\mathbf{1 . 7 5}$ & 1.27 \\
\hline Rata-Rata Industri & $\mathbf{3 . 2 4}$ & $\mathbf{3 . 8 0}$ & $\mathbf{3 . 3 6}$ & $\mathbf{3 . 5 4}$ & $\mathbf{3 . 9 8}$ & 3.58 \\
\hline Perkembangan & - & $\mathbf{1 7 . 5 0}$ & $-\mathbf{1 1 . 7 7}$ & $\mathbf{5 . 4 8}$ & $\mathbf{1 2 . 3 6}$ & $\mathbf{5 . 8 9}$ \\
\hline
\end{tabular}

Sumber: data olahan

Berdasarkan Tabel 2 diatas, dapat dilihat bahwa rata-rata industri tertinggi pada data perputaran modal kerja sebesar 3,98\% di tahun 2016 dan terendah pada tahun 2012 sebesar 3,24\%, sedangkan untuk nilai perkembangan tertinggi sebesar 17,50\% di tahun 2013. PT Kimia Farma Tbk, PT Merck Tbk dan PT Pyridam Farma Tbk memiliki nilai cenderung menurun tiap tahunnya, sedangkan 5 (lima) emiten yang mengalami fluktuasi. Pada data perputaran modal kerja ini PT Pyridam Farma Tbk memiliki rata-rata tertinggi, yaitu sebesar 4,75\% sedangkan rata-rata terendah adalah PT Darya Varia Laboratoria Tbk sebesar $2,82 \%$. 
Susi Artati, Pengaruh DER, Perputaran Modal Kerja dan Ukuran Perusahaan Terhadap NPM pada Industri Farmasi Yang Listing di Bursa Efek Indonesia Periode 2012-2016

Tabel 3

Perkembangan Ukuran Perusahaan pada Industri Farmasi di Bursa Efek Indonesia Periode 2012-2016

\begin{tabular}{|c|l|c|c|c|c|c|c|}
\hline \multicolumn{1}{|c|}{$\begin{array}{c}\text { Noma } \\
\text { Emiten }\end{array}$} & $\mathbf{2 0 1 2}$ & $\mathbf{2 0 1 3}$ & $\mathbf{2 0 1 4}$ & $\mathbf{2 0 1 5}$ & $\mathbf{2 0 1 6}$ & Rerata \\
\hline $\mathbf{1}$ & \multicolumn{1}{|c|}{ PT Darya-Varia Laboratoria Tbk } & 13.89 & 13.99 & 14.55 & 16.06 & 13.25 & 14.35 \\
\hline $\mathbf{2}$ & PTIndofarma Tbk & 11.82 & 15.35 & 13.00 & 13.99 & 14.07 & 13.65 \\
\hline $\mathbf{3}$ & PT Kimia Farma Tbk & 14.72 & 16.24 & 13.45 & 12.07 & 15.50 & 14.40 \\
\hline $\mathbf{4}$ & PT Kalbe Farma Tbk & 13.52 & 14.03 & 14.04 & 14.90 & 16.34 & 14.57 \\
\hline $\mathbf{5}$ & PT Merck Tbk & 13.48 & 12.06 & 15.54 & 14.09 & 14.13 & 13.86 \\
\hline $\mathbf{6}$ & PT Pyridam Farma Tbk & 14.24 & 14.99 & 16.43 & 13.37 & 11.98 & 14.20 \\
\hline $\mathbf{7}$ & PT Tempo Scan Pacific Tbk & 15.65 & 14.23 & 14.27 & 14.21 & 15.27 & 14.73 \\
\hline $\mathbf{8}$ & PT Merck Sharp Dhome Pharma Tbk & 16.50 & 13.48 & 11.98 & 15.69 & 14.27 & 14.38 \\
\hline Tertinggi & $\mathbf{1 6 . 5 0}$ & $\mathbf{1 6 . 2 4}$ & $\mathbf{1 6 . 4 3}$ & $\mathbf{1 6 . 0 6}$ & $\mathbf{1 6 . 3 4}$ & $\mathbf{1 6 . 3 1}$ \\
\hline Terendah & $\mathbf{1 1 . 8 2}$ & $\mathbf{1 2 . 0 6}$ & $\mathbf{1 1 . 9 8}$ & $\mathbf{1 2 . 0 7}$ & $\mathbf{1 1 . 9 8}$ & $\mathbf{1 1 . 9 8}$ \\
\hline Rata-Rata Industri & $\mathbf{1 4 . 2 3}$ & $\mathbf{1 4 . 3 0}$ & $\mathbf{1 4 . 1 6}$ & $\mathbf{1 4 . 3 0}$ & $\mathbf{1 4 . 3 5}$ & $\mathbf{1 4 . 2 7}$ \\
\hline Perkembangan & - & $\mathbf{0 . 4 8}$ & $-\mathbf{0 . 9 7}$ & $\mathbf{0 . 9 9}$ & $\mathbf{0 . 3 8}$ & $\mathbf{0 . 2 2}$ \\
\hline
\end{tabular}

Sumber: data olahan

Berdasarkan Tabel 3 diatas, dapat dilihat bahwa rata-rata industri tertinggi sebesar 14,35\% pada tahun 2016, sedangkan terendah pada tahun 2014 sebesar 14,16\%, dengan nilai perkembangan tertinggi sebesar 0,99\% pada tahun 2015. Dapat dilihat pada PT Kimia Farma Tbk dan PT Tempo Scan Pacific Tbk mengalami kenaikan secara terus menerus setiap tahunnya, sedangkan PT Merck Sharp Dhome Pharma Tbk cenderung menurun, terutama pada tahun 2014 dan 5 (lima) emiten lainnya mengalami fluktuasi yang cenderung meningkat setiap tahunnya.

Tabel 4

Perkembangan Net Profit Margin pada Industri Farmasi di Bursa Efek Indonesia Selama Periode 2012-2016

\begin{tabular}{|c|l|c|c|c|c|c|c|}
\hline \multicolumn{1}{|c|}{$\begin{array}{c}\text { Nama } \\
\text { Emiten }\end{array}$} & $\mathbf{2 0 1 2}$ & $\mathbf{2 0 1 3}$ & $\mathbf{2 0 1 4}$ & $\mathbf{2 0 1 5}$ & $\mathbf{2 0 1 6}$ & Rerata \\
\hline $\mathbf{1}$ & \multicolumn{1}{|c|}{ PT Darya-Varia Laboratoria Tbk } & 13.69 & 11.42 & $\mathbf{7 . 3 3}$ & 8.26 & 11.93 & 10.53 \\
\hline $\mathbf{2}$ & PT Indofarma Tbk & 3.67 & -4.05 & 0.08 & 0.40 & -3.50 & -0.68 \\
\hline $\mathbf{3}$ & PT Kimia Farma Tbk & $\mathbf{5 . 3 9}$ & 4.96 & 5.23 & 5.20 & 4.47 & $\mathbf{5 . 0 5}$ \\
\hline $\mathbf{4}$ & PT Kalbe Farma Tbk & 13.02 & 12.31 & 12.21 & 11.50 & 12.08 & 12.22 \\
\hline $\mathbf{5}$ & PT Merck Tbk & 11.59 & 14.69 & 21.02 & 14.49 & 15.54 & 15.47 \\
\hline $\mathbf{6}$ & PT Pyridam Farma Tbk & 3.00 & 3.22 & 1.20 & 1.42 & 1.78 & 2.12 \\
\hline $\mathbf{7}$ & PT Tempo Scan Pacific Tbk & 9.58 & 9.32 & $\mathbf{7 . 7 8}$ & 6.47 & 6.87 & 8.00 \\
\hline $\mathbf{8}$ & PT Merck Sharp Dhome Pharma Tbk & -4.08 & -2.99 & -6.47 & 6.16 & 9.28 & 0.38 \\
\hline Tertinggi & $\mathbf{1 3 . 6 9}$ & $\mathbf{1 4 . 6 9}$ & $\mathbf{2 1 . 0 2}$ & $\mathbf{1 4 . 4 9}$ & $\mathbf{1 5 . 5 4}$ & 15.89 \\
\hline Terendah & $\mathbf{- 4 . 0 8}$ & $\mathbf{- 4 . 0 5}$ & $\mathbf{- 6 . 4 7}$ & $\mathbf{0 . 4 0}$ & $\mathbf{- 3 . 5 0}$ & -3.54 \\
\hline Rata-Rata Industri & $\mathbf{6 . 9 8}$ & $\mathbf{6 . 1 1}$ & $\mathbf{6 . 0 5}$ & $\mathbf{6 . 7 4}$ & $\mathbf{7 . 3 1}$ & 6.64 \\
\hline Perkembangan & - & $\mathbf{- 1 2 . 5 0}$ & $-\mathbf{1 . 0 2}$ & $\mathbf{1 1 . 4 1}$ & $\mathbf{8 . 4 4}$ & 1.58 \\
\hline
\end{tabular}

Sumber: data olahan

Berdasarkan Tabel 4 dapat dilihat bahwa perkembangan industri tertinggi sebesar $11,41 \%$ pada tahun 2015. Untuk rata-rata industri terendah sebesar 6,05\% pada tahun 2014 dan tertinggi sebesar 7,31\% pada tahun 2016. Sedangkan untuk nilai rata-rata tertinggi adalah PT Merck Tbk yaitu sebesar 15,47\% dan yang terendah adalah PT Indofarma Tbk sebesar $(0,68 \%)$. Pada PT Indofarma Tbk dan PT Tempo Scan Pacific Tbk mengalami nilai net profit margin yang cenderung menurun, sedangkan 6 (enam) emiten lainnya 
Susi Artati, Pengaruh DER, Perputaran Modal Kerja dan Ukuran Perusahaan Terhadap NPM pada Industri Farmasi Yang Listing di Bursa Efek Indonesia Periode 2012-2016

mengalami fluktuasi tiap tahunnya. Penelitian ini bertujuan untuk menganalisis pengaruh Debt to Equity Ratio, Perputaran Modal Kerja dan Ukuran Perusahaan terhadap Net Profit Margin pada industri farmasi di Bursa Efek Indonesia secara simultan dan parsial selama periode 2012-2016.

\section{METODE}

Metode yang digunakan penulis dalam penelitian ini adalah metode deskriptif, data yang dikumpulkan dalam penelitian ini adalah data Sekunder, metode pengumpulan data yaitu Data yang digunakan dalam penelitian ini dikumpulkan dari laporan keuangan industri farmasi yang listing di Bursa Efek Indonesia selama periode 2012-2016 diperoleh dari situs resmi Indonesian Stock Exchange (www.idx.co.id), Metode analisis data yang digunakan dalam penelitian ini adalah metode analisis deskriptif kuantitatif. Alat analisis yang digunakan ialah Persamaan Regresi Linear Berganda, untuk dapat menyelesaikan penelitian ini data dan informasi yang dikumpulkan dari laporan keuangan industri farmasi yang terdaftar di BEI periode 2012-2016 kemudian dianalisis dengan menggunakan alat model regresi linier berganda (Ghozali, 2011). Adapun model analisis regresi linier berganda yang digunakan adalah sebagai berikut :

$\mathrm{Y}=\mathrm{a}+\mathrm{b}_{1} \mathrm{X}_{1}+\mathrm{b}_{2} \mathrm{X}_{2}+\mathrm{b}_{3} \mathrm{X}_{3+} \mathrm{e}$

\section{HASIL}

Variabel yang digunakan dalam penelitian ini terdiri dari 3 variabel bebas dan 1 variabel terikat, variabel bebas yang digunakan yaitu Debt to Equity Ratio $\left(\mathrm{X}_{1}\right)$, Perputaran Modal Kerja $\left(\mathrm{X}_{2}\right)$ dan Ukuran Perusahaan $\left(\mathrm{X}_{3}\right)$. Sedangkan variabel terikat yang digunakan dalam penelitian ini adalah Net Profit Margin (Y). Pengujian hipotesis yang dilakukan terhadap analisis regresi menunjukkan ada tidaknya pengaruh antara variabel independen yaitu debt to equity ratio, perputaran modal kerja dan ukuran perusahaan (size) yang di masukkan kedalam model regresi dengan variabel dependen yaitu net profit margin. Berdasarkan uji hipotesis yang dilakukan diperoleh hasil sebagai berikut Berdasarkan hasil pengujian hipotesis (uji F) pada model regresi secara simultan diperoleh nilai signifikan sebesar 0,012 >0,05 (taraf signifikasi). Selain itu dapat dilihat juga dilihat hasil perbandingan antara $\mathrm{f}_{\text {hitung }}$ dan $\mathrm{f}_{\text {tabel }}$ yang menunjukan $\mathrm{f}_{\text {hitung }}$ sebesar 4,169 , sedangkan $f_{\text {tabel }}$ sebesar 2,87. Dari hasil tersebut terlihat bahwa $f_{\text {hitung }}>f_{\text {tabel }}$ yaitu 4,169>2,87, maka dapat disimpulkan bahwa secara simultan variabel independen debt to equity ratio, perputaran modal kerja dan ukuran perusahaan (size) berpengaruh signifkan terhadap variabel dependen net profit margin. Hal ini menunjukkan bahwa net profit margin yang terjadi pada Industri Farmasi dapat dipengaruhi oleh debt to equity ratio, perputaran modal kerja dan ukuran perusahaan (size).

Hasil perbandingan antara $t_{\text {hitung }}$ dan $t_{\text {tabel }}$ yang menunjukan $t_{\text {hitung }}$ sebesar 1,218 , sedangkan $t_{\text {tabel }}$ sebesar 2,030. Dari hasil tersebut terlihat bahwa $t_{\text {hitung }}<t_{\text {tabel }}$ yaitu 1,218 $<2,030$, maka dapat disimpulkan bahwa secara parsial variabel debt to equity ratio tidak berpengaruh signifikan terhadap variabel dependen net profit margin. Hasil perbandingan antara $t_{\text {hitung }}$ dan $t_{\text {tabel }}$ yang menunjukan $t_{\text {hitung }}$ sebesar 2,602, sedangkan $t_{\text {tabel }}$ sebesar 2,030. Dari hasil tersebut terlihat bahwa $t_{\text {hitung }}>t_{\text {tabel }}$ yaitu $2,602>1,689$, maka dapat disimpulkan bahwa secara parsial variabel perputaran modal kerja berpengaruh signifikan terhadap variabel dependen net profit margin. Hasil perbandingan antara $t_{\text {hitung }}$ dan $t_{\text {tabel }}$ yang menunjukan $t_{\text {hitung }}$ sebesar 1,199 , sedangkan $t_{\text {tabel }}$ sebesar 2,030. Dari hasil tersebut terlihat bahwa $t_{\text {hitung }}<t_{\text {tabel }}$ yaitu $1,199<2,030$, maka dapat disimpulkan bahwa secara parsial variabel ukuran perusahaan tidak berpengaruh signifikan terhadap variabel dependen net profit margin. Berdasarkan hasil pengujian koefisien determinasi, menunjukkan bahwa nilai R Square sebesar 0,258 yang artinya bahwa variabilitas variabel dependen yang dapat dijelaskan oleh variabel independen yaitu debt to equity ratio, perputaran modal kerja dan ukuran perusahaan dalam penelitian ini adalah sebesar $25,8 \%$, sedangkan sisanya $74,2 \%$ dijelaskan oleh variabel-variabel lain di luar model penelitian yang digunakan.

\section{SIMPULAN}

Berdasarkan hasil analisis diatas maka peneliti dapat menarik kesimpulan sebagai berikut: Hasil pengujian secara simultan menunjukkan model regresi secara simultan diperoleh nilai signifikan sebesar $0,012>0,05$ (taraf signifikasi). Selain itu dapat dilihat juga dilihat hasil perbandingan antara $F_{\text {hitung }}$ dan $F_{\text {tabel }}$ 
yang menunjukan $\mathrm{F}_{\text {hitung }}>\mathrm{F}_{\text {tabel }}$, maka dapat disimpulkan bahwa secara simultan variabel independen debt to equity ratio, perputaran modal kerja dan ukuran perusahaan (size) berpengaruh terhadap variabel dependen net profit margin pada Industri Farmasi selama periode 2012-2016. Hasil perbandingan antara $\mathrm{T}_{\text {hitung }}$ dan $\mathrm{T}_{\text {tabel }}$ yang menunjukan $\mathrm{T}_{\text {hitung }}<\mathrm{T}_{\text {tabel }}$ maka dapat disimpulkan bahwa $\mathrm{H}_{\mathrm{o}}$ diterima $\mathrm{H}_{\mathrm{a}}$ ditolak artinya secara parsial variabel debt to equity ratio tidak berpengaruh signifikan terhadap variabel dependen net profit margin. Hasil perbandingan terlihat bahwa $\mathrm{T}_{\text {hitung }}>\mathrm{T}_{\text {tabel }}$ maka dapat disimpulkan bahwa $\mathrm{H}_{\mathrm{o}}$ ditolak $\mathrm{H}_{\mathrm{a}}$ diterima artinya secara parsial variabel perputaran modal kerja berpengaruh signifikan terhadap variabel dependen net profit margin. Dan hasil perbandingan menunjukan $\mathrm{T}_{\text {hitung }}<\mathrm{T}_{\text {tabel }}$ maka dapat disimpulkan bahwa $\mathrm{H}_{0}$ diterima $\mathrm{H}_{\mathrm{a}}$ ditolak artinya secara parsial variabel ukuran perusahaan tidak berpengaruh signifikan terhadap variabel dependen net profit margin.

\section{DAFTAR PUSTAKA}

Ghozali. I, 2011. Metode Penelitian Kombinasi Ekonometrika: Teori, Konsep dan Aplikasidengan SPSS 17. UniversitasDiponegoro. Semarang.

Kansil, 2001. Hukum Perusahaan Indonesia, PT. Pradnya Paramita, Jakarta.

Nugroho, 2011, Skripsi : Analisis Pengaruh Likuiditas, Pertumbuhan Penjualan, Perputaran Modal Kerja, Ukuran Perusahaan dan Leverage Terhadap Profitabilitas Pada Perusahaan Manufaktur, UNDIP, Semarang (dipublikasikan) 